\title{
Estimation of the Kinetic Parameters of a Catalytic Cracking Model Case Study
}

\author{
CRISTINA POPA*, NICOLETA NICOLAE, CRISTIAN PATRASCIOIU \\ Petroleum-Gas University of Ploiesti, 39 Bucuresti Blvd., 100680, Ploiesti, Romania
}

\begin{abstract}
This paper presents the research regarding determination of kinetic model parameters from a catalytic cracking process. Starting from the Weekman kinetic model, the authors proposed a simplified version of this model and, based on experimental data form a catalytic cracking plant, they have numerical determined the coefficients of the new kinetic model. For this purpose, there were defined two objective functions; the first function is based on errors generated by estimation of the riser outlet temperature and the second function associated to the errors generated by the estimation of the gasoline yield. The minimization of the two objective functions has been solve by using Optimization Toolbox from MATLAB programming language. The results showed that the objective function that depends on gasoline yield allows more accurate estimation of the kinetic parameters from this model.
\end{abstract}

Keywords: kinetic model, optimization, catalytic cracking

Generally, for a chemical processes and especially for the catalytic cracking process, the kinetic model is responsible for the accuracy of the process model results. These kinetic models are different by pseudo-components number, chemical reactions number and the complexity of the kinetic equations. The number of pseudocomponents of the kinetic models is continuous increased in order to obtain a more detailed prediction of products distribution [1]. For example, the first kinetic model proposed by Weekman, it is based on three major pseudocomponents: feedstock, gasoline and coke plus light gas [2].

Relevant contributions to improve this kinetic model are presented in following papers [3-5]. Lee, in the [6] paper, there has dividing the third pseudo-components in two different components in coke and light gasses and obtaining a model with 4-lumps. Anchetya, in his work [7], presents a 5-lump model, considering the coke one pseudcomponent and divided the gas in two pseudocomponents (liquefied gasses and dry gas).

Hagelberg expanded this model in a 8-lump model by dividing the gasoline fraction into paraffin's, olefins, naphthenes and aromatics [8]. For the heavy feedstock's Chiyoda Chemical Engineering and Construction Co. have developed a 6-lump kinetic model, where the feedstock have been divided in two components: residue and heavy gasoil, and the reaction products obtained are: light gasoline, gasoline, gases and coke [9]. Some authors have developed more complex kinetic models, such as 10-lump model [10,11], 12-lump model [13], 13-lump model [14], 19-lump model [15]. These kinetic models are mathematically more complex and they need many coefficients, which are hard to estimate.
Determination of kinetic model coefficients is realised by minimizing an objective function whose structure defined as a sum of errors squared of the selected output variable, deviations calculated based on experimental data and the values determined based on the kinetic model and the reactor model. The process output variable chosen depending on the consistency of experimental data or model sensitivity. The techniques of minimizing the objective function are part for the category of multidimensional optimization algorithms with restrictions [16].

In this context, the authors' researches have oriented to study the coefficients associated with the Weekman kinetic model, following simplification of model and determining the new coefficients.

\section{Weekman kinetic model}

The model elaborated for the catalytic cracking processing vacuum distillate; on which starting point are three pseudo-components: A -feedstock; B -gasoline; Ccoke + gasses. The kinetic scheme of the Weekman model represented in figure 1 and the chemical reactions occurring in the riser shown in Table 1.

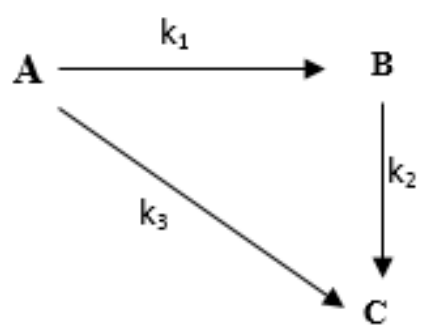

Fig.1. Weekman kinetic scheme

\begin{tabular}{|c|c|c|c|}
\hline No. & Reaction & $\begin{array}{c}\text { Reaction velocity } \\
{\left[\frac{k g_{\text {produs }}}{k g_{\text {react }} \times s}\right]}\end{array}$ & $\begin{array}{c}\text { Activation energy } \\
{[\mathrm{kcal} / \mathrm{mol}]}\end{array}$ \\
\hline 1 & $\mathrm{~A} \longrightarrow \mathrm{B}$ & $r_{1}$ & 10000 \\
\hline 2 & $\mathrm{~B} \longrightarrow \mathrm{C}$ & $r_{2}$ & 18000 \\
\hline 3 & $\mathrm{~A} \longrightarrow \mathrm{C}$ & $r_{3}$ & 10000 \\
\hline
\end{tabular}

Table 1

CHEMICAL REACTIONS IN WEEKMAN KINETIC MODEL

* email: ceftene@upg-ploiesti.ro 
The following relations express the third velocity reactions from Weekman kinetic scheme:

$$
\begin{aligned}
& r_{1}=-k_{1} * Y_{A}^{2} ; \\
& r_{2}=-k_{2} * Y_{B} \\
& r_{3}=-k_{3} * Y_{A}^{2},
\end{aligned}
$$

where:

$$
k_{1}, k_{2^{\prime}} k_{3} \text {-velocity reaction constants, }\left[\frac{k_{g_{\text {produs }}}}{k g_{\text {react }} \times s}\right] \text {; }
$$

$Y_{A}$ - weight fraction of the feedstock in the reaction average;

$Y_{\beta}$ - weight fraction of gasoline in the reaction average;

$Y^{\beta}$ - weight fraction of gas and coke in the reaction average.

The velocity reaction constants $k_{1}, k_{2}, k_{3}$ are dependent on the feedstock composition, riser temperature, equilibrium catalyst activity and the process operating conditions. These velocity reaction constants can be calculated based on Wollaston's relation [17]:

$$
\begin{aligned}
& k_{j}=k_{j}^{0} \cdot f_{j}(M A T) \cdot \theta_{j}\left(t_{c}\right) \cdot \\
& \gamma_{j}\left(c_{c o c s}\right) \cdot e^{\left(\frac{E_{j}}{R}\right)\left(\frac{1}{T_{0}}-\frac{1}{T}\right)}, \quad j=1, \ldots, 3,
\end{aligned}
$$

where $\mathrm{k}^{\circ}$ is velocity reaction constant of the at $482^{\circ} \mathrm{C}$, expressed in $\mathrm{s}^{-1}$.

The rest of elements of the equation (4) have the following meanings $[4,18]$ :

$\mathrm{f}_{\mathrm{i}}(\mathrm{MAT})$-attenuation function, that takes in consideration the effect of the equilibrium catalyst's activity;

$\theta_{(}(t)$ - attenuation function, that takes in consideration the effect of the coke catalyst's deactivation;

$y_{i}\left(c_{c o c s}\right)$ - attenuation function, that takes in consideration the effect of the residual coke;

$\mathrm{E}_{\mathrm{j}}$ - activation energy of the chemical reaction, $\left[\frac{\mathrm{kcal}}{\mathrm{mol}}\right]$;

$T$ - current riser temperature, $[\mathrm{K}]$;

$T_{0}$-set point temperature, $[\mathrm{K}]$;

$R$ - universal gas constant, $\left[\frac{\mathrm{m}^{3} \cdot \mathrm{atm}}{\mathrm{kmol} \cdot \mathrm{K}}\right]$.

The reactor model of the catalytic cracking

The catalytic cracking reactor is a system with distributed parameters; authors in the paper $[4,18]$ have presented the model. The model contains a differential equations system, based on material and heat balance.

$$
\left\{\begin{array}{l}
\left.\frac{d Y_{A}}{d z}=-\frac{1}{U_{v}}\left(k_{1}+k_{3}\right) Y_{A}^{2}\right) \\
\frac{d Y_{B}}{d z}=\frac{1}{U_{v}}\left(k_{1} Y_{A}^{2}-k_{2} Y_{B}\right) \\
\frac{d Y_{C}}{d z}=\frac{1}{U_{v}}\left(k_{2} Y_{B}+k_{3} Y_{A}^{2}\right) \\
\frac{d T_{r}}{d z}=\left(-\frac{d Y_{A}}{d z}\right) * \frac{\left(-\Delta H_{r 1}\right)}{\left(Y_{A} c_{p, A}+R_{a b w} c_{p a b w}+R_{c a f} f_{p c a t}\right)}
\end{array}\right.
$$

The initial conditions used to solve the differential equations system (5) are:

$$
\left\{\begin{array}{c}
Y_{A}(0)=1 \\
Y_{B}(0)=0 \\
Y_{C}(0)=0 \\
T(0)=T_{\text {nod }}
\end{array}\right.
$$

The significance of the measures used in the model is the following:

$U_{v}$ - riservapours velocity expressed by relationship

$$
U_{V}=\frac{1}{3600} * \frac{Q_{m p}}{\rho_{v} * A_{r} * E} ;
$$

$Q_{\text {mp - }}$ feedstock flow $\left[\frac{\mathrm{kg}}{\mathrm{h}}\right]$;

$A_{r}$ - the cross-sectional area of the riser $\left[\mathrm{m}^{2}\right]$;

$\rho_{\mathrm{v}}$ - density in vapour phase inside riser $\left[\frac{\mathrm{kg}}{\mathrm{m}^{3}}\right]$;

$E$ - volume fraction of the catalysts;

$\Delta \mathrm{H}_{\mathrm{r} 1}$ - enthalpy of the first reaction $\left[\frac{\mathrm{kcal}}{\mathrm{kg} \text { comp. reac. }}\right]$;

$\mathrm{Q}_{\mathrm{A}^{\prime}} \mathrm{Q}_{\mathrm{B}^{\prime}} \mathrm{Q}_{\mathrm{cj}}$ - pseudo-component weight rate $\left[\frac{\mathrm{kg}}{\mathrm{h}}\right]$ :

$\mathrm{Q}_{\text {cat }}{ }^{-}$catalyst weight flow $\left[\frac{\mathrm{kg}}{\mathrm{h}}\right]: ;$

$\mathrm{Q}_{\text {abur }}$ - steam weight flow $\left[\frac{\mathrm{kg}}{\mathrm{h}}\right]$ :

Simplifying the kinetic model Weekman and objective function development

Starting from kinetic model Weekman completed with Wollaston's relationships, the authors simplified velocity constants expressions and proposing following relations

$$
k_{j}=k_{j}^{0} e^{\left(\frac{E_{j}}{R}\right)\left(\frac{1}{T_{0}}-\frac{1}{T}\right)}, j=1, \ldots, 3^{(8)}
$$

in which we have the following variable:

$\mathrm{E}_{\mathrm{j}}$ - activation energy of reaction, $\left[\frac{\mathrm{kcal}}{\mathrm{mol}}\right]$;

$T$ - current riser temperature, $[\mathrm{K}]$;

$T_{0}$ - set point temperature, $[\mathrm{T}]$;

$R$ - universal gas constant, $\left[\frac{\mathrm{m}^{3} \cdot \mathrm{atm}}{\mathrm{kmol} \cdot \mathrm{K}}\right]$.

In the kinetic relation (1-3), the activation energy has values taken from literature, Table 1 [19]. Giving up of Wollaston's relations implies the recalculation of velocity constant $k^{\circ}, j=1, \ldots, 3$ from experimental date. In Table 2 are represented the experimental data that are used to recalculate the velocity constant of the reaction at $482^{\circ} \mathrm{C}$.

Determination of the velocity constants $k_{i}^{0}, j=1, \ldots, 3$ related to reaction velocity are realized by minimization the following objective function

$$
f_{o b}\left(k_{1}^{0}, k_{2}^{0}, k_{3}^{0}\right)=\sum_{j=1}^{m}\left[T_{j}^{\text {exp }}-T_{j}^{\text {calc }}\left(k_{q}^{0}, k_{2}^{0}, k_{3}^{0}\right)\right]^{2}
$$


where $T^{\text {exp }}$ represents the experimental riser temperature; $T^{\text {cal }}\left(\mathrm{k}_{1}^{0}, \mathrm{k}_{2}{ }^{0}, \mathrm{k}_{3}{ }^{0}\right)$ - the temperature calculated with reactor model, for the same values of input data from experimental set $j$.

For the transformation reaction of the feedstock in gas and coke, the special literature indicates the value $\mathrm{k}_{3}^{\circ}=0.05$ $\mathrm{S}^{-1}$, value adopted by the authors. In this condition, the objective function (9) is

$$
f_{o b}\left(k_{1}^{0}, k_{2}^{0}\right)=\sum_{j=1}^{m}\left[T_{j}^{\exp }-T_{j}^{\text {calc }}\left(k_{1}^{0}, k_{2}^{0}\right)\right]^{2} .
$$

Considering the multivariable character of the function (10) and the structure of mathematical model of the reactor (5), the determination of a function minim can be done using al gorithm, dedicated for the nonlinear function.

\section{Programming the optimization problem}

The optimization problem was solved using the MATLAB programming environment. In this environment, the Optimization Tool is used, respectively fmincon routine, figure 2. This routine is dedicated to calculate the optimum pointfor nonlinear multivariable functions under nonlinear restrictions. The objective function is programmed in the riser_optim module, the initial solution chosen for values

$\left[\begin{array}{c}1 \\ 0.5\end{array}\right]$ and the interval of research for each of both variables of function (10) is $\left[\begin{array}{l}0 \\ 2\end{array}\right]$.

Table 2

EXPERIMENTAL DATA FROM CATALYTIC CRACKING PLANT

\begin{tabular}{|c|c|c|c|c|c|c|c|c|c|c|}
\hline & \multicolumn{4}{|c|}{ Feedstock property } & \multicolumn{6}{|c|}{ Operated data } \\
\hline ด̆ & $\begin{array}{l}\text { 密 } \\
\text { 口 }\end{array}$ & 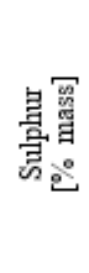 & 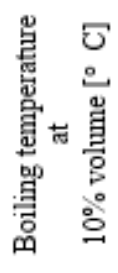 & 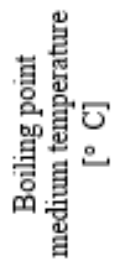 & 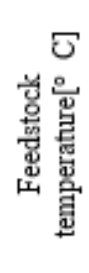 & 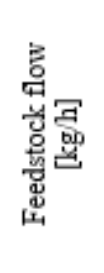 & 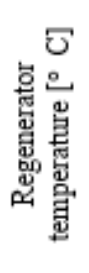 & 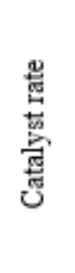 & 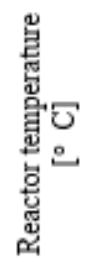 & 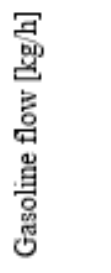 \\
\hline 1 & 0.912 & 0.40 & 299 & 378 & 203 & 176292 & 711 & 4.67 & 531 & 75417 \\
\hline 2 & 0.914 & 0.40 & 286 & 370 & 200 & 177083 & 710 & 4.36 & 531 & 82917 \\
\hline 5 & 0.907 & 0.35 & 263 & 364 & 207 & 155667 & 706 & 4.68 & 530 & 69375 \\
\hline 6 & 0.907 & 0.32 & 262 & 365 & 205 & 161083 & 708 & 4.56 & 530 & 75583 \\
\hline 8 & 0.908 & 0.37 & 284 & 367 & 194 & 157792 & 711 & 4.63 & 531 & 71167 \\
\hline 9 & 0.911 & 0.35 & 275 & 367 & 195 & 161750 & 709 & 4.59 & 531 & 74167 \\
\hline 12 & 0.907 & 0.32 & 281 & 366 & 191 & 169542 & 711 & 4.54 & 532 & 78333 \\
\hline 13 & 0.906 & 0.33 & 282 & 370 & 198 & 170375 & 710 & 4.49 & 531 & 80208 \\
\hline 14 & 0.906 & 0.34 & 280 & 363 & 205 & 173167 & 710 & 4.57 & 531 & 80417 \\
\hline 15 & 0.910 & 0.36 & 287 & 368 & 205 & 167333 & 712 & 4.48 & 531 & 79300 \\
\hline
\end{tabular}

A Optimication Tool

Ele Help

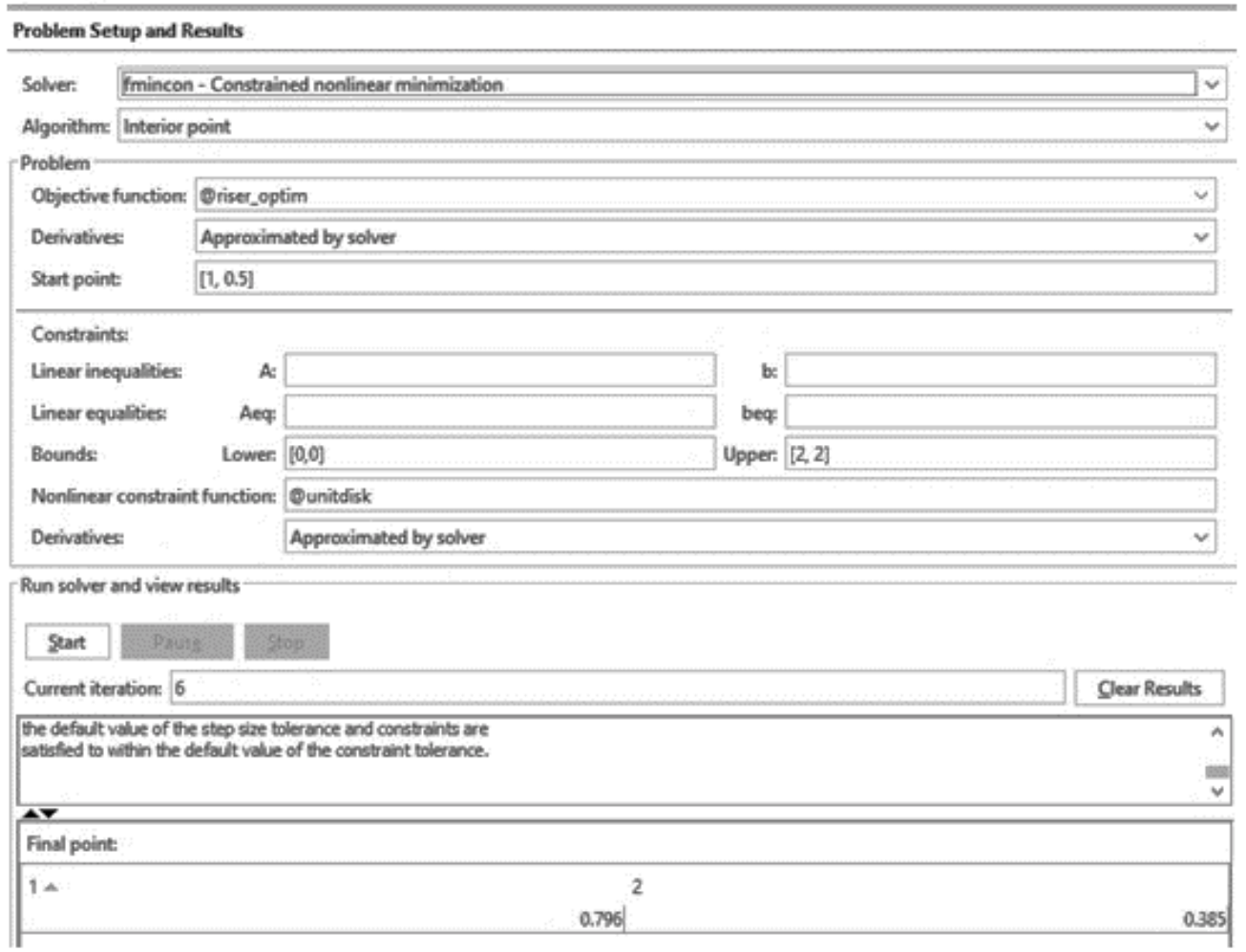

Fig. 2. Interface Optimization Tool 
The implementation of the objective function in MATLAB has raised programming problems due to language specificity respectively a reduced possibility of the date transfer between the program modules. The objective function module is implemented as a riser_optim function

$$
\text { function } S=\text { riser_optim }(x)
$$

where $x$ variable represents the vector which contains the values of velocity reaction constant at $482^{\circ} \mathrm{C}$, respectively $\mathrm{k}_{\mathrm{i}}^{0} ; \mathrm{S}$ - the value of the objective function (10).

In this programming mode, the function can be subordinated to optimization module because the function variables are the independent variables by the optimizer module. In order to be able to calculate the deviation square sum from relation (10), it was defined an iterative structure with $m$ iteration, which can realize the following operations:

a) Download into the reactor model variables the experimental input data associated to experiment $j$;

b) Calculate using heat balance the value of the mixing node temperature. This temperature represents one of the initial conditions of a differential equation system associate to the catalytic cracking reactor;

c)Integration of differential equation system using ode23s function. This function gives back the results calculated by integrating differential equations system as matrix of $[z, y]$, where $z$ is the vector associated with to current point from riser, and ycontains several numbers of vectors associated to integrated variable;

d)The calculation of the squared deviation of the riser temperature and the summing of deviations defined in relation (10).

The mathematical model of catalytic cracking reactor contains the kinetic model and material mass balance and heat balance equations. The reactor model is implemented in MATLAB by a multivariable function:

where the variables are:

$$
\text { function } \operatorname{dyd} z=f(z, y, u, k 0)
$$

$\mathrm{dy} / \mathrm{dz}$-vector that contains the value of the mathematical model derivatives;

z-current position;

$y$-vector that contains components concentration;

u- vector that contains the values of the input experimental model measurements;

$k_{o}$ - reaction velocity constants vector at $482^{\circ} \mathrm{C} \mathrm{k}_{\mathrm{j}}^{0}$.

\section{Results and discussions}

Running the optimization programme there were followed three objectives: testing optimizer algorithm stability, the influence of the initial solution and the determination of simplified Weekman model coefficients.

The numerically tests show a strong relation between algorithm stability and initial solution. For some initializations solutions values we get optimal values between a short range and the objective function is almost constant. In figure 3 it is represented the action module of the optimization programme, and the conclusion is that the optimization algorithm is faster closing to the optimum point and after this step followed by a slowly movement to it.

This evolution is demonstrating the fact that the objective function is characterized by a plateau evolution around the optimum point.

The optimization algorithm performance was study by the behaviour of the objective function near the optimal point, figure 4. The conclusion is that the function minim is not too well defined; reversed banana evolution is much more relevant.

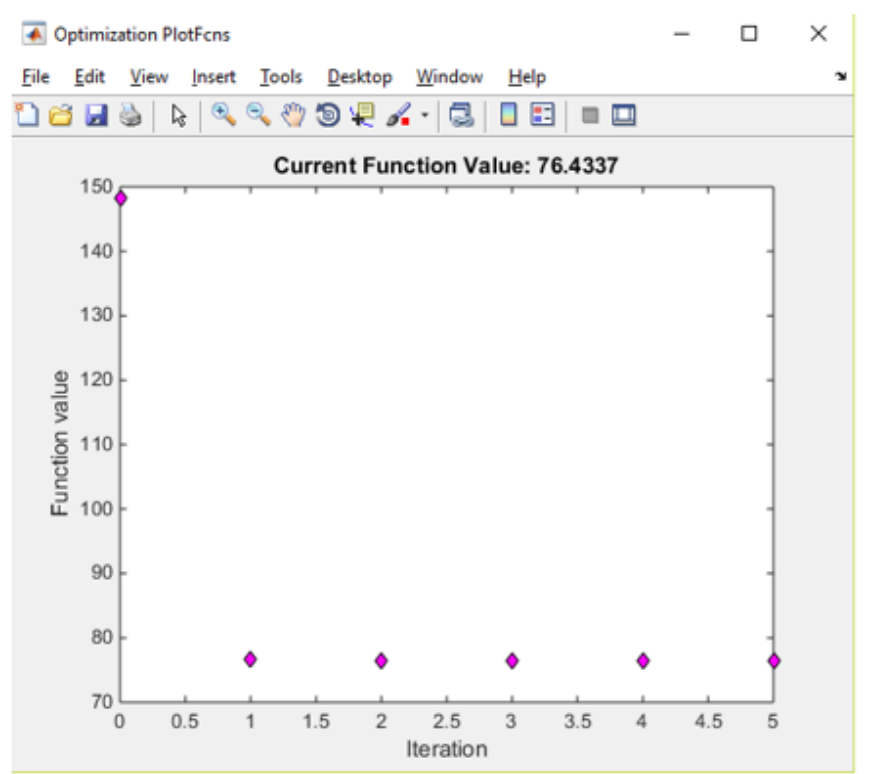

Fig. 3. Objective function values evolution

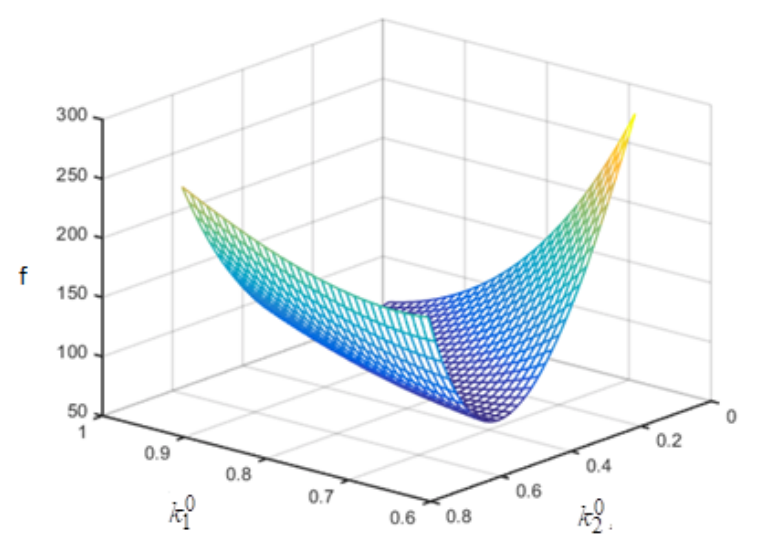

Fig. 4. Objective function graphic representation

Analysis of contour curves associated to objective function, figure 5 , validates the previously formulated hypothesis. It is found that these contour curves are extremely elongated confirms the reverted banana aspect of the objective function. In these conditions, the determination of the optimum point can be extremely difficult.

Another conclusion resulting from this analysis was the need to reduce the initialization interval of the solutions (searching interval). Looking on equation (10), objective function has the $T^{2}$ signification. At an average of 76 and for 15 experimental points, the resulted average deviation

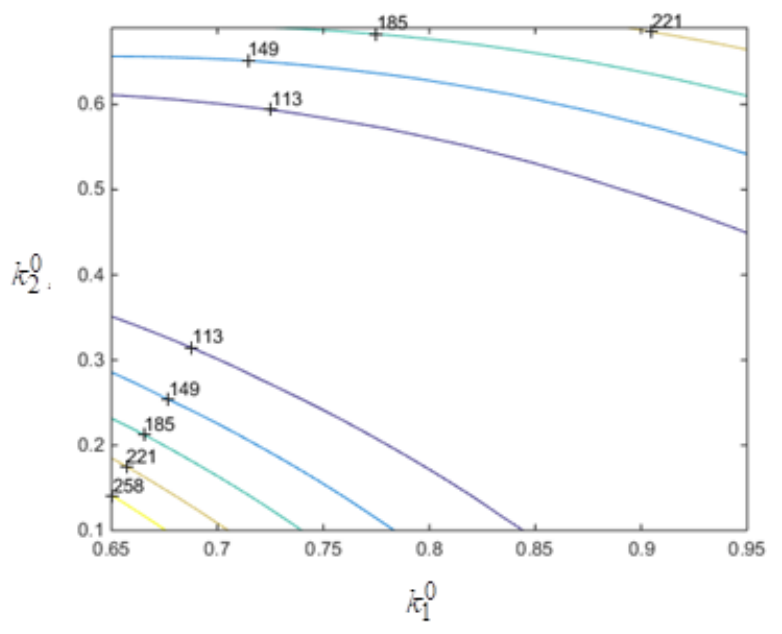

Fig. 5. Contour curves of objective function 


\begin{tabular}{|c|c|c|c|c|c|}
\hline & \multicolumn{2}{|c|}{ X0 } & \multicolumn{2}{c|}{ Xopt } & Fob \\
\hline \multirow{2}{*}{ Group 1 } & 0.65 & 0.10 & 0.96 & 0.18 & 76.36 \\
\cline { 2 - 6 } & 0.70 & 0.19 & 0.99 & 0.20 & 79.75 \\
\hline \multirow{2}{*}{ Group 2 } & 0.75 & 0.29 & 0.79 & 0.35 & 77.79 \\
\cline { 2 - 6 } & 0.80 & 0.39 & 0.80 & 0.37 & 76.44 \\
\hline \multirow{2}{*}{ Group 3 } & 0.65 & 0.29 & 0.74 & 0.41 & 76.93 \\
\cline { 2 - 6 } & 0.65 & 0.60 & 0.84 & 0.36 & 76.93 \\
\hline
\end{tabular}

Table 3

THE RESULTS OBTAINED DURING PROCESS OPTIMIZATION RESULTS

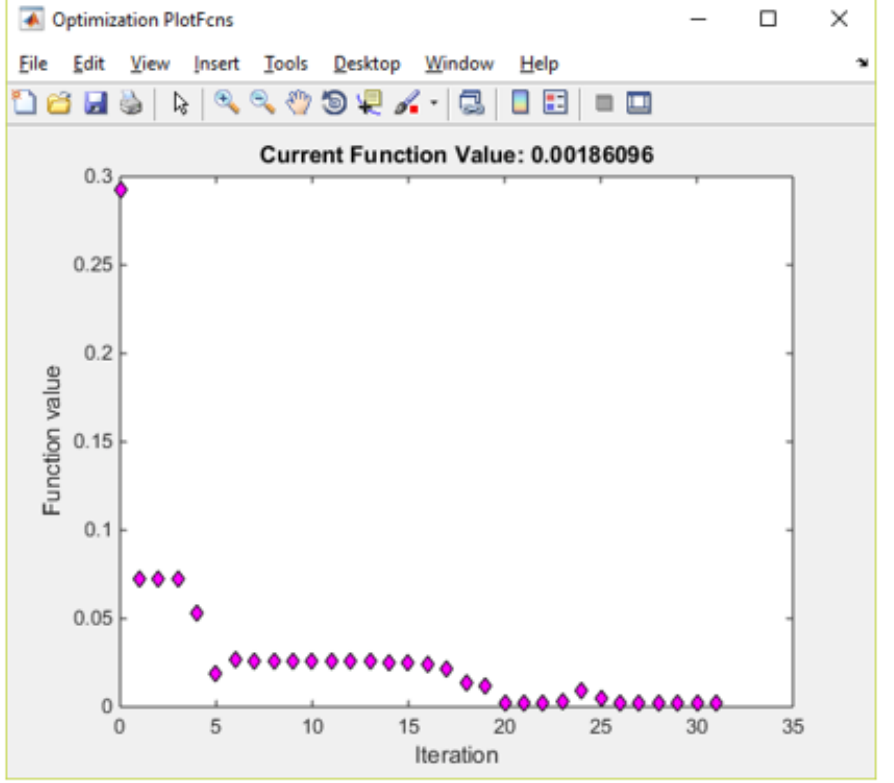

Fig. 6. Evolution of the objective function value to minimize the function (11)

of $2.25^{\circ} \mathrm{C}$ is obtained, the accepted value for the estimated kinetic purposed constants for Weekman kinetic model. Table 3 contains some of the obtained results from already run optimizing tests.

The results can be grouped in three categories based on the optimum solution value. It is noticed that the optimum solution values are different, and more for the second variable, $\mathrm{k}^{\circ}$.

The high value of the objective function suggests that the temperature at the riser outlet is not suitable for determining the coefficients of the kinetic model. In support of this statement, the authors indicate that the temperature measured in the riser is in fact a controlled temperature and implicitly its value is not sensitive to the input variables of the mathematical model of the process. In this case, the authors investigated the possibility of using another objective function, which would allow for the determination of coefficients of the kinetic model with better precision.

Because the experimental database contains information about the feed rate and gasoline flow obtained, and assuming the plant is stationary without mass accumulation regimes, the gasoline yield is given by the ratio of the two flows. In these conditions, the objective function (10) becomes:

$$
f_{o b}\left(k_{1}^{0}, k_{2}^{0}\right)=\sum_{j=1}^{m}\left[\eta_{j}^{\operatorname{sap}}-\eta_{j}^{\text {caic }}\left(k_{1}^{0}, k_{2}^{0}\right)\right]^{2} .
$$

Minimizing the objective function (11) was performed using the same MATLAB function, respectively fmicon. The initial values of the optimum point were considered [0.5; 0.5 ] and the optimum interval for this researcher $k_{1}{ }^{\circ} \in$ $[0.1 \ldots 2]$ and $k_{2}{ }^{0} \in[0.1 \ldots 2]$.

Figure 6 shows the evolution of the objective function value during the iterations. It is observed that after the first
Table 4

INFLUENCE OF THE INITIAL SOLUTION ON STABILITY AND OPTIMAL SOLUTION

\begin{tabular}{|l|l|l|l|l|}
\hline \multicolumn{2}{|c|}{ X0 } & \multicolumn{2}{c|}{ Xopt } & Fob \\
\hline 1.0 & 1.00 & 1.45 & 0.970 & 0.00190 \\
\hline 2.0 & 0.50 & 1.54 & 1.000 & 0.00185 \\
\hline 1.2 & 0.65 & 1.35 & 0.924 & 0.00187 \\
\hline 1.4 & 0.75 & 1.45 & 0.979 & 0.00186 \\
\hline 1.6 & 0.85 & 1.51 & 1.020 & 0.00180 \\
\hline 1.8 & 0.95 & 1.47 & 0.960 & 0.00186 \\
\hline
\end{tabular}

5 iterations, the optimal function evolves to a plateau, the function value slowly decreasing or remaining constant. Iterations 20 ... 30 highlight the near-constant evolution of the value of the objective function.

The stability of the optimization algorithm is tested by running the program for different initial values of the optimal solution and the values in Table 4 are eloquent in this respect.

In these conditions, the authors believe the optimization algorithm has determined the optimal solution $\mathrm{k}_{1}^{0}=1.43$ and $k_{2}^{\circ}=0.79$.

The graphical representation of function (11), Figure 7 , highlights the existence of a tolerable range of variables $\mathrm{k}^{\circ}$ and $\mathrm{k}_{2}^{\circ}$, a domain which is bounded by a wall of the objective function (11), a wall that reflects a large and abrupt increase in the value of the objective function.

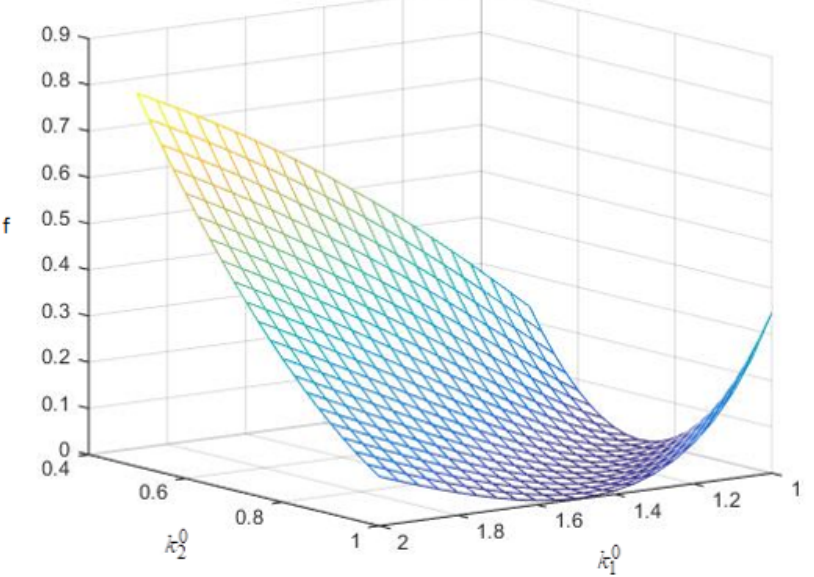

Fig. 7. 3D representation of an objective function (11).

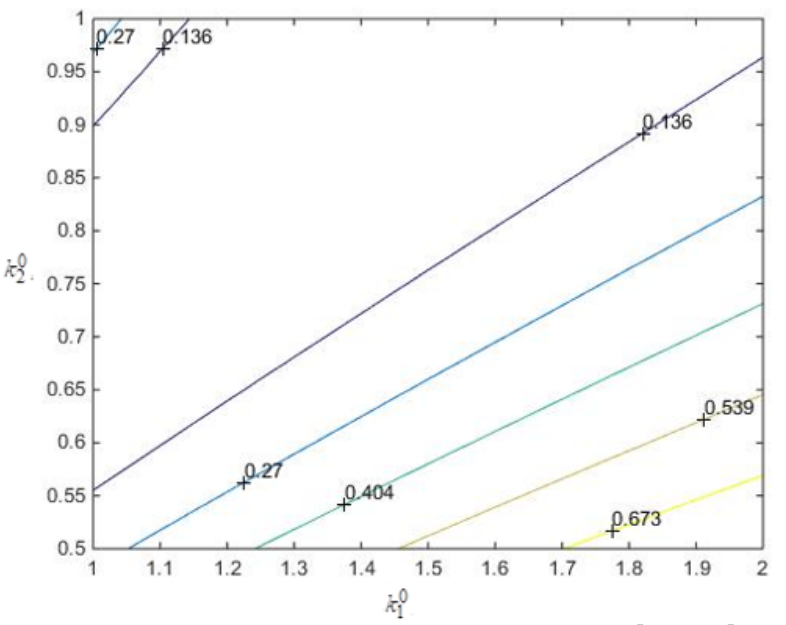

Fig. 8. Function (11) surface protection in plan $\mathrm{k}_{1}{ }^{\circ}, 0, \mathrm{k}_{2}{ }^{0}$ 
The interior of the domain leads to a similar area with the graphical representation of the function Rosenbrooke, respectively the banana function [20]. The analysis performed demonstrates that the choice of the initial solution is decisive for the stability of the algorithm.

Figure 8, projection of the response surface on the plane $\mathrm{k}^{\circ}, 0, \mathrm{k}^{0}$, represents a new argument to sustain what was said before. It is noticed that the feasibility zone of the minimum function (11) is a strip bounded by the lens function wall.

\section{Conclusions}

In this paper, numerical aspects regarding the estimation of the parameters of the Weekman kinetic model, simplified model of authors, are treated with experimental data from a catalytic cracking industrial plant. The main contributions of the authors are as follows:

-Elaboration of two objective functions, one related to the errors generated by the estimation of the outlet temperature from the riser and the second one associated to the errors generated by the estimation of the gasoline efficiency;

-Minimizing these functions was done using the Optimization Tool from MATLAB programming language;

-A plate around the optimum point characterizes the objective function associated with errors generated by the estimation of the outlet temperature. In these conditions, the minimum of this is not very well defined and the estimation of the kinetic model parameters is difficult.

-The objective function associated with the errors generated by the estimation of the gasoline yield has a graphical representation, which indicates an area of existence of the banana end, which defines a tolerable range for model parameters much better than the one associated with the first objective function. Using this function, the constants of the proposed kinetic model were calculated.

\section{References}

1.BOLLAS, G., LAPPAS, A.A., IARTRIDIS, D. K., Catalysis Today, 127, 2007, p. 31.
2.WEEKMAN, V. W. J r., Ind. Eng. Chem. Proc. Des. Dev., 7, 1968, p. 90. 3.ARBEL, A., HUANG, Z., RINARD, I. H., SHINNAR, R., SAPRE, A., Ind. Eng. Chem. Res., 34, 1995, p. 1228.

4.POPA, C., PATRASCIOIU C., Rev. Chim., (Bucharest), 60, no. 4, 2010, p. 419.

5.ROSCA, P., BOLOCAN, I., DRAGOMIR, R., Rev. Chim., (Bucharest), 66, no. 5, 2015, p 419.

6.LEE, L.S., CHEN, Y.W., HUANG, T.N., PAN, W.Y., Canadian J. Chem. Eng., 67, 1989, p. 615.

7.ANCHEYTA, J.J., LOPEZ, I.F., AGUILAR, E.R., Applied Cat., 177, 1999, p. 227.

8.HAGELBERG, P., EILOS, I., HILTUNEN J., LIPIÄINEN K., NIEMI, V.M., Applied Cat, 223, 2002, p.73.

9.TAKATSUKA, T., SATO S., MARIMATO, Y., HASHIMATO, H. J., J . J apan Petr. Ins., 27, 1984, p. 6.

10.J ACOB, J. C., GROSS, B., VOLTZ, S.E., WEEKMAN, V.W., AICHE J., 22, 1976, p. 701.

11. KRAEMER, D. W., DE LASA, H. I., AIChE Annual Meeting ,1988.

12.CERQUEIRA, H S., BISCAIA, E.C. JR, SOUSA-AGUIAR, E.F., Appl. Cat., 164, 1997, p.35.

13.OLIVEIRA, L.L., Estimaçâo de Parâmetros e Avaliaçâo de Modelos de Craqueamento Catalítico., M.Sc. Thesis (in Portuguese), University Federal do Rio de Janeiro, 1987.

14. SAI, P.R.K., JOHN, D.A., NARENDRA, N.B., Can. J. Chem. Eng., 73, 1995, p. 484.

15.PITAULT, I., FORISSIER, M., BERNARD, J.R., Can. J. Chem. Eng., 73, 1995, p. 494.

16.PATRASCIOIU, C., Tehnici de numerice optimizare, Editura MatrixRom, 2005.

17. WOLLASTON, E.G., HAFLIN, W.I., FORDW. D., Oil and Gas J., 22, 1975, p. 87.

18.POPA, C., PATRASCIOIU, C., Buletinul Scientific al Univesitatii Timisoara, Seria Chimica si Ingineria Mediului, 1995, p.35.

19.BELISTIANS, M., Conducerea evoluatã a sistemului reactorregenerator din instalatia de cracarea catalitica, Teza de doctorat, Universitatea Petrol-Gaze din Ploiesti, 1992.

20.PARDALOS, P.M., RESENDE, M.G.C., Handbook of Applied Optimization, Oxford University, Press, New York , 2002.

Manuscript received: 30.01 .2019 